\title{
VIBRATION TRANSMISSIBILITY STUDY OF HIGH DENSITY SOLID WASTE BIOPOLYMER FOAM
}

\author{
Najibah Ab Latif and Anika Zafiah M. Rus ${ }^{*}$ \\ Sustainable Polymer Engineering, \\ Advanced Manufacturing \& Materials Center (AMMC), \\ Faculty of Mechanical and Manufacturing Engineering, \\ Universiti Tun Hussein Onn Malaysia, \\ 86400, Parit Raja, Batu Pahat, Johor, Malaysia \\ Email: gbahmaahadian99@gmail.com, zafiah@uthm.edu.my* \\ *Corresponding author
}

\begin{abstract}
Waste cooking oils are problematic to dispose of especially in the developed countries. In this paper, waste cooking oil is used as raw material to produce foam. The purpose of this study is to develop a high density solid biopolymer foam (HDB) by using a hot compression molding technique based on flexible and rigid cross-linking agents. Physical properties such as scanning electron microscopy (SEM) and vibration characteristics have been studied using a vibration transmissibility test according to the ASTM D3580-95 standard. Different thicknesses were examined during the fabrication of HDB to measure the vibration property. By using the linear vibration theory with a single degree of freedom, the resonance frequency of vibration transmissibility and damping ratios of HDB foam at variation excitation are acquired. The results show that HDB flexible foam gives a higher damping ratio to absorb vibration. The capability of the HDB flexible foam to absorb vibration is greater than rigid HDB. It was observed that no improvement was achieved by increasing the thickness of HDB to vibration transmissibility. Reducing the thickness of the HDB flexible foam gives an increment of a damping ratio up to $36 \%$.
\end{abstract}

Keywords: High density solid; foam; vibration transmissibility test.

\section{INTRODUCTION}

In Malaysia, the options for disposing of used cooking oil are limited. Disposal is difficult because used cooking oil is usually in a liquid or semi-solid form and the solid waste regulations restrict the disposal of liquids in landfills (SWP, 2012). Waste cooking oil must not be poured down drains or sewers because this inevitably leads to blockages and odour or vermin problems and may also pollute watercourses, leading to problems for wildlife (FSA, 2012; SWP, 2012). Other disposal methods can also be problematic. Open burning of used cooking oil causes black smoke, which is prohibited (FSA, 2012). Since protecting the environment has emerged as one of the hottest global trends, it is important for firms to understand how to design and manage green products (Su, Wang, \& Ho, 2010). In this paper, biopolymer foams were produced by using waste cooking oil monomer. In previous research, flexible polyurethane foams produced from the polycondensation of polyols with isocyanate were formed by open cells and had high gas permeability, low density and limited mechanical strength (Saunders \& Frisch, 1978; Ulrich, 1983). Due to this situation, the waste biopolymer foam was used 
for fabrication into HDB by using a hot compression technique. (Vaidya et al., 2006) used liquid molding techniques to fabricate metal foam with a composite sandwich structure, which is gaining recognition for high performance applications in a variety of commercial and defense industries. Furthermore, mechanical and physical properties of foam were examined in previous studies, and the ability of polymeric foam to absorb the energy of vibration lies behind a wide variety of applications in the automotive industry, for packaging and transportation of fragile goods (Zaretsky, Asaf, Ran, \& Aizik, 2012). Vibration will relate to the damping property, but in this case the capability of vibration absorption on the HDB was observed. The dynamic properties such as stiffness and damping of the material determine the level of the transmission of vibration through the material (Rivin, 2003). In most applications, a high damping capacity, expressed by the damping ratio, is desired (Vaidya et al., 2006). Our study will provide further understanding of the vibration characteristics and the morphological and physical properties of the HDB based on rigid and flexible cross-linking agents.

\section{EXPERIMENTAL}

\section{Raw Materials}

The raw materials for the HDB fabrication are: biopolymer based on waste cooking oil monomer (Rus, 2009a, 2009b, 2010; Rus, Kemp, \& Clark, 2008), rigid isocyanate or flexible isocyanate. The flexible isocyanate is polymethane polyphenyl isocyanate (modified polymeric-MDI) (viscosity at $25^{\circ} \mathrm{C}=120-160 \mathrm{cps}$, specific gravity at $25^{\circ} \mathrm{C}=$ $1.18-1.20 \mathrm{~g} / \mathrm{ml}$, NCO content, $\%$ wt $=26.3-27.3$ ) while the rigid isocyanate is polymethane polyphenyl isocyanate (diisocyanate-diphenylmethane-MDI). The weight of compositions was determined regarding the monomer and isocyanate with a ratio of 2:1.

\section{Foam Production}

The polyol based waste cooking oil monomer and isocyanate were stirred with a Philips Multiple Speeds Handmixer in a cup for 15 seconds (Rus, 2009b). The mixtures were then immediately cast in an open mold before the foam could expand out. It was left for 12 hours at room temperature to cure or solidify (Rus, 2010).

\section{Waste Granulate Biopolymer Preparation}

The biopolymer foam was cut into small cubes and ground using a grinding machine. The size of the final particles or granulate of biopolymer foam used in this research was approximately $0.08 \mathrm{~mm}$.

\section{Hot Compression}

$160 \mathrm{~g}$ waste granulate foam was weighed to fill in the mold with an internal core size of $180 \times 180 \times 15 \mathrm{~mm}$ to produce HDB with dimensions $180 \times 180 \times 6 \mathrm{~mm}$ after a hot compression technique. The parameter of the compression machine was set to $90^{\circ} \mathrm{C}$, with 26 tonnes of 1 hour compression time. Using this method, two samples were prepared, namely HDB based on rigid and flexible cross-linking agents. Each sample of 
the flexible and rigid HDB was cut into nine samples with dimensions $50 \times 50 \times 6 \mathrm{~mm}$, as shown in Figure 1.

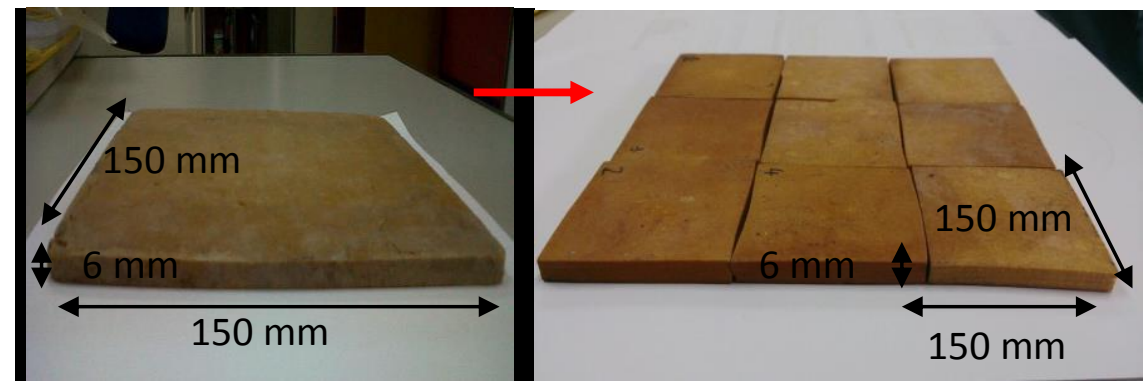

Figure 1. Dimensions of HDB

\section{Scanning Electron Microscope}

The HDB surfaces were examined using SEM (JEOL-JSM6380LA). Each HDB sample was mounted on a holder using double-sided tape and then sputter-coated with gold to impart electrical conductivity and reduce charging artifacts (Alonso, Auad, \& Nutt, 2006) by using an auto fine coater (JEOL-JFC1600). The operation voltage of the SEM was $10 \mathrm{kV}$ with a $40 \mu \mathrm{m}$ magnifier under low vacuum.

\section{Density Test}

The density test of the HDB was conducted by preparing a cube of $10 \times 10 \times 6 \mathrm{~mm}$. The weights of the HDB were measured using Mettler Toledo Laboratory Weighing. This test was carried out according to ASTM D3574-08. The densities of HDB were calculated as Eq. (1), where $\rho=$ density, $m=$ mass of foam and $v=$ volume of foam. The average density of the four samples of HDB is tabulated in Table 1.

Table 1. Physical and mechanical properties of HDB.

\begin{tabular}{cccc}
\hline HDB sample & $\begin{array}{c}\text { Mass } \\
(\mathrm{g})\end{array}$ & $\begin{array}{c}\text { Thickness } \\
(\mathrm{mm})\end{array}$ & Density $\left(\mathrm{g} / \mathrm{cm}^{\wedge} 3\right)$ \\
\hline Flexible (F) & 0.7605 & 6.10 & 1.2467 \\
Rigid (R) & 0.7540 & 6.35 & 1.1874 \\
\hline
\end{tabular}

$$
\rho=\mathrm{m} / \mathrm{v}
$$

\section{Vibration Transmissibility Test}

The vibration transmissibility of HDB was measured using the HDB foam system shown in Figure 2. A UCON vt-9008 data acquisition system analysis package (VSC software) was used to make the measurements. The test was performed according to the ASTM D3580-95 standard test method for vibration testing (vertical linear motion) (Wong \& Schueneman, 1997). Figure 2 illustrates the HDB foam system. Four pieces of flexible $\mathrm{HDB}$ foam and four pieces of rigid HDB foam were prepared with dimensions $50 \times 50 \times 6 \mathrm{~mm}$ to run the vibration transmissibility test. Six HDB samples were examined with three different thicknesses for both flexible and rigid HDB. 
Transmissibility tests were generated at various base excitation levels, (i) $1 \mathrm{~mm}$ and 1.5 $\mathrm{mm}$, and (ii) $0.1 \mathrm{~g}$ and $0.15 \mathrm{~g}$ in frequency range of $15-23 \mathrm{~Hz}$ and $18-26 \mathrm{~Hz}$ respectively. Only two blocks, that is $482.95 \mathrm{~g}$, were loaded onto the moveable top plate and locked on the sliding top plate. Two Kistler accelerometers were initially attached to the base and sliding top plates to measure the vibration amplitude of the base plate (input) and the response of mass (output) to the base excitation. In this system, a vertical amplitude, $\mathrm{y}(\mathrm{t})$ was initially given at the shaking table but the total amplitude, $\mathrm{x}(\mathrm{t})$ received by the cylindrical blocks (mass) was read from the moveable top plate. Due to the static creep exhibited by the HDB foam, the whole system was then allowed to rest for 30 minutes to reach a static equilibrium before the vibration test began (Joshi, Bajaj, \& Davies, 2010; White et al., 2000). The vibration test was started by a start button in the VCS software and automatically stopped after reaching the maximum frequency for both excitations. There were a total of three trials for each HDB foam sample.

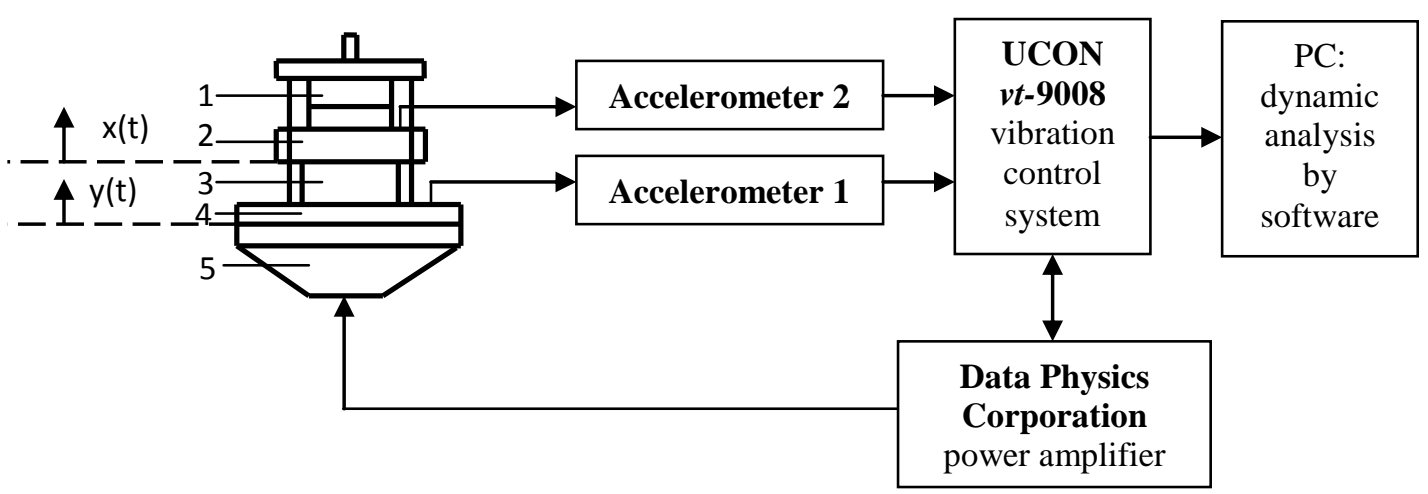

Figure 2. Schematic diagram of HDB foam system: (1) load; (2) sliding top plate; (3) HDB foam; (4) base plate; (5) shaker

Table 2. Sandwich layer of HDB in vibration test

\begin{tabular}{ccccccc}
\hline HDB sample & FF & FFF & FFFF & RR & RRR & RRRR \\
\hline Thickness $(\mathrm{mm})$ & 12.2 & 18.3 & 24.4 & 12.7 & 19.05 & 25.4 \\
\hline
\end{tabular}

\section{RESULTS AND DISCUSSION}

\section{Density Analysis}

Density is related to the mass of the waste HDB granulates. The density of the fabricated HDB foams should be similar to each other since the mass of waste granulates is $160 \mathrm{~g}$. It is well known that the higher the density, the higher the weight of HDB obtained (Thomson, 1993). Based on Figure 3, the densities of flexible HDB are higher than the densities of rigid HDB due to the porosity structure. As mentioned in previous research (Dai et al., 2005), a higher cell density offers better damping. 


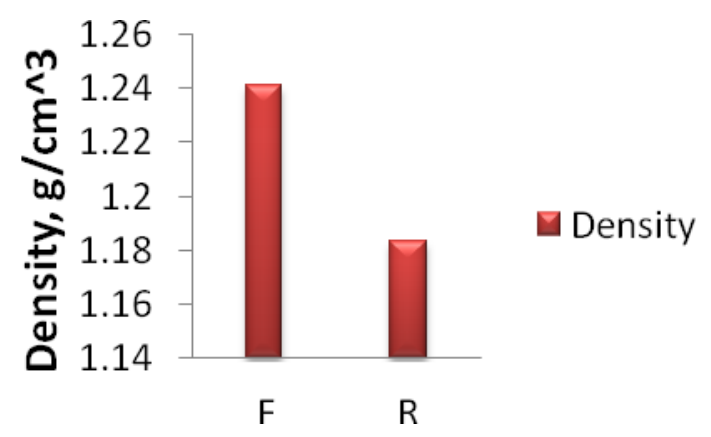

Figure 3. Density results for flexible and rigid samples

\section{Microscopy}

In this study, the morphologies of the HDB surface were investigated. The SEM images of the surfaces are shown in Figure 4(a) and Figure 4(b). The fabricated flexible HDB samples show larger pores and are more compact, while the rigid HDB has fewer small pores and is fluffy in appearance. These can be proven by the porosity measurement on the HDB surfaces. The level of porosity is presented in Figure 5. The structure morphologies according to the SEM results were an influence on the vibration transmissibility of the material.

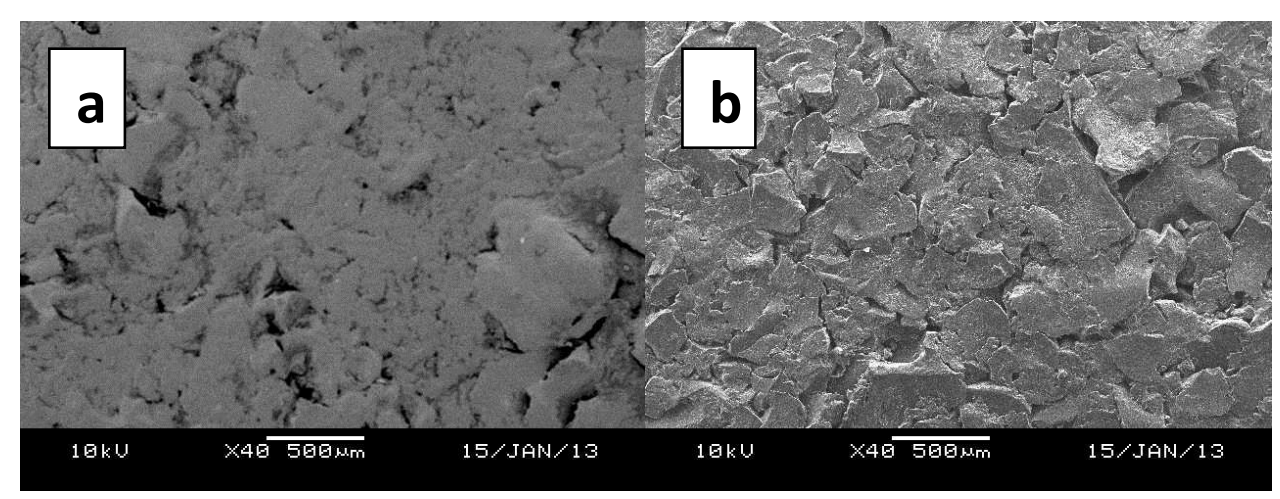

Figure 4. SEM images of HDB foam: a) flexible; b) rigid

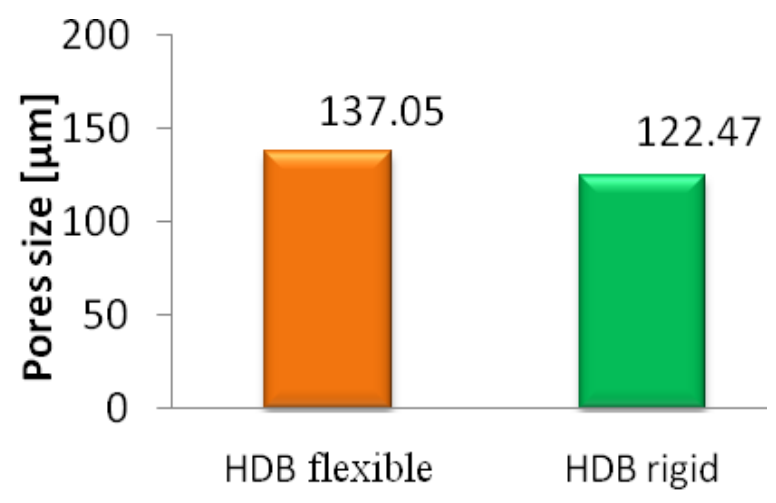

Figure 5. Pores size of flexible and rigid HDB 


\section{Vibration Analysis}

The results of the vibration transmissibility test were plotted and analyzed in terms of transmissibility versus frequency, as shown in Figures 6 to 9. The curves illustrated in Figures 6,8 and 9 show that all the tested specimens gave similar transmissibility behavior, no matter what the displacement or acceleration base excitation levels. The experimental results in Figures 6, 7, 8(a) and 9(a) showed that when the thickness increases, the resonance peak will increase, with Figures 8(b) and 9(b) being the exception. From the results, it was observed that when the base excitation increases from $1 \mathrm{~mm}$ to $1.5 \mathrm{~mm}$ (or $0.1 \mathrm{~g}$ to $0.15 \mathrm{~g}$ ), the resonance and attenuation frequency will shift to lower values, as will the resonance peak, but some fluctuating data were also found. This is actually caused by the decrease of the damping with the increase of the base excitation in vibration testing in high density solids. According to a previous study, the decrease of resonance frequency in an HDB system with multilayers may be due to changes in the stiffness of the HDB during the experiment (Ravi Sankar, Vamsi Krishna, Bhujanga Rao, \& Bangaru Babu, 2010). However, the increment of resonance peak was found because of the damping reduction obtained in the HDB foam system (Inman \& Singh, 2001). The resonance frequency shifted toward higher values when the thickness of the HDB foam decreased in the systems, although some fluctuating data were observed. Overall, the system with HDB FF and RR foam inserted achieved the highest resonance frequency during the transmissibility test, but this situation was not replicated in Figures 7(a) and 7(b). It can be observed that the resonance frequencies for HDB FF are $21.39 \mathrm{~Hz}$ for $1 \mathrm{~mm}, 18.51 \mathrm{~Hz}$ for $1.5 \mathrm{~mm}, 24.27 \mathrm{~Hz}$ for $0.1 \mathrm{~g}$ and $24.11 \mathrm{~Hz}$ for $0.15 \mathrm{~g}$. By contrast, the resonance frequencies of HDB RR are $21.31 \mathrm{~Hz}$ for $1 \mathrm{~mm}$, $18.49 \mathrm{~Hz}$ for $1.5 \mathrm{~mm}, 24.27 \mathrm{~Hz}$ for $0.1 \mathrm{~g}$ and $23.87 \mathrm{~Hz}$ for $0.15 \mathrm{~g}$. The increased resonance frequency in the HDB foam system according to the thickness decrement of HDB inserted may be due to the slow and weak response in the system. During the transmissibility test, some of the amplitudes (vibrations) were absorbed by the HDB foam due to its damping effects. Some of them were dissipated due to frictional losses occurring in the uniaxial motion of the moveable top plate (White et al., 2000).
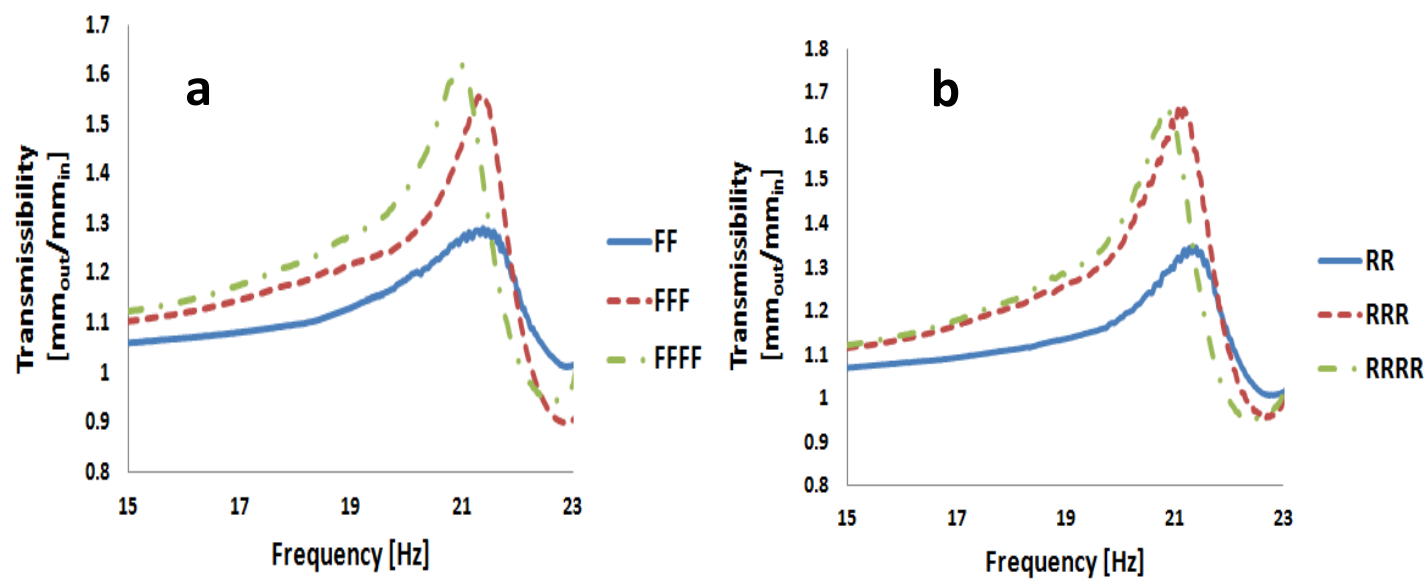

Figure 6. Displacement transmissibility from base to moveable top plate at $1 \mathrm{~mm}$ base excitation: (a) flexible HDB and (b) rigid HDB 

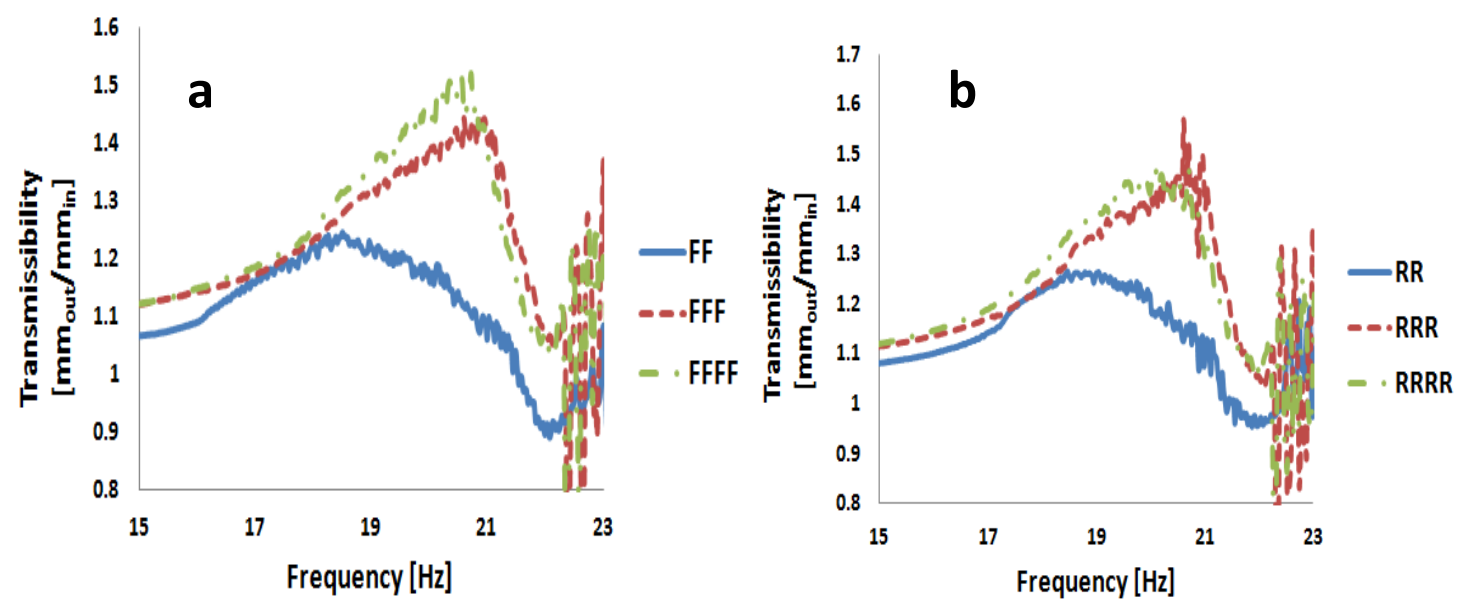

Figure 7. Displacement transmissibility from base to moveable top plate at $1.5 \mathrm{~mm}$ base excitation: (a) flexible HDB and (b) rigid HDB
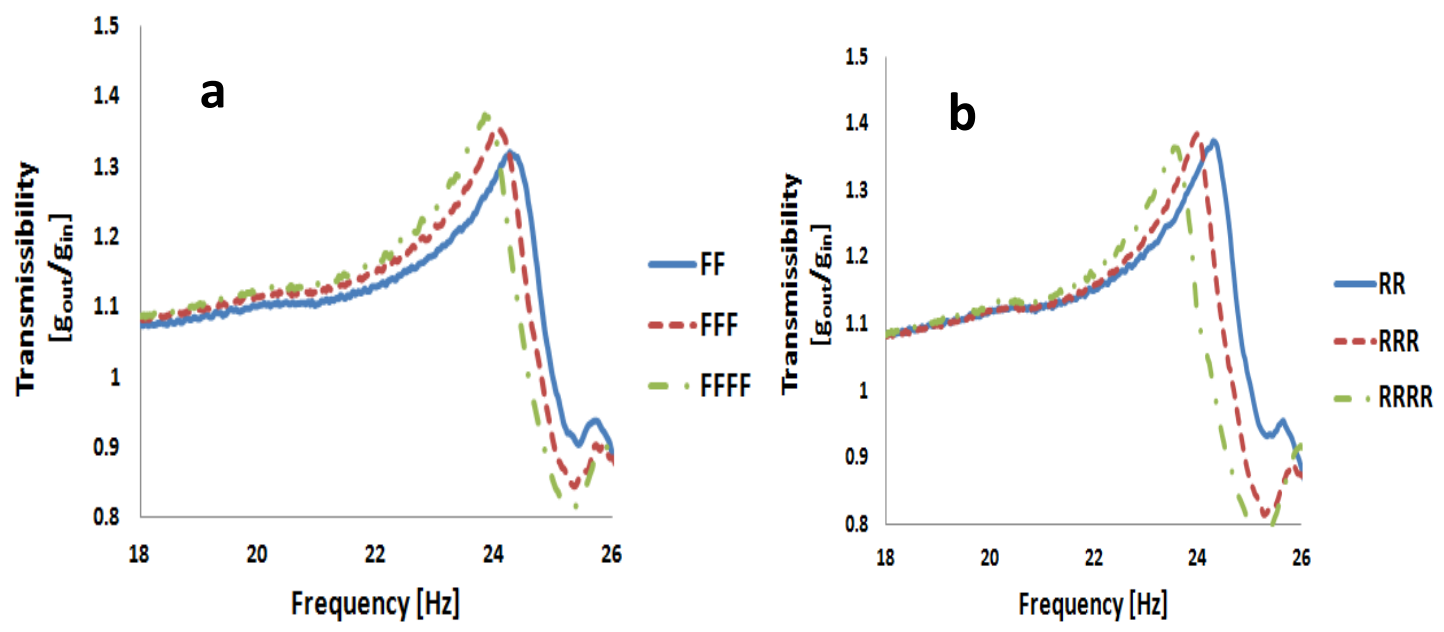

Figure 8 . Acceleration transmissibility from base to moveable top plate at $0.1 \mathrm{~g}$ base excitation: (a) flexible HDB and (b) rigid HDB
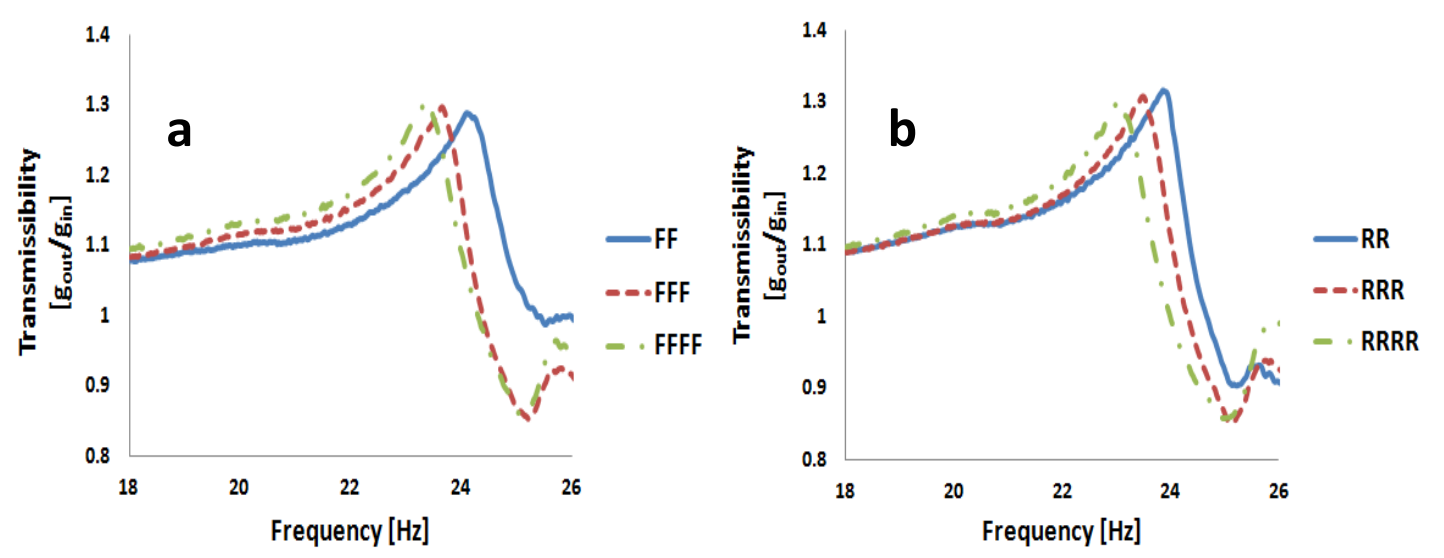

Figure 9. Acceleration transmissibility from base to moveable top plate at $0.15 \mathrm{~g}$ base excitation: (a) flexible HDB and (b) rigid HDB 


\section{Damping Analysis}

For the vibration test system in Figure 2, the mass block on the HDB foam specimen system may be idealized as a linear single degree of freedom (SDOF) system, as shown in Figure 10. Similar modeling was used in the studies of White et al. (2000) and Joshi et al. (2010).

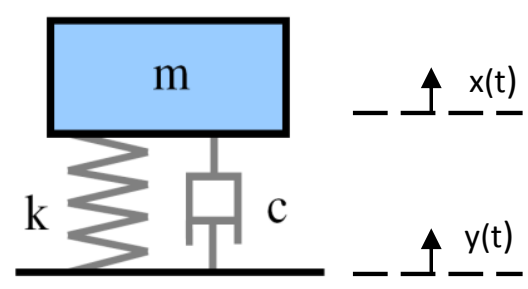

Figure 10. The HDB foam system modeled as a mass-spring damper system

SDOF with viscous damping and the vibration transmissibility $\operatorname{Tr}$ can be described as

$$
T_{r}=\sqrt{\frac{1+(2 \xi \lambda)^{2}}{(1-\lambda)^{2}+(2 \xi \lambda)^{2}}}
$$

where $\lambda$ stands for the frequency ratio $(\lambda=f / f r), f$ is the excitation frequency of the vibration table, $f r$ is the resonance frequency of the HDB foam, and $\zeta$ represents the damping ratio. It is evident that the vibration transmissibility has a close relationship with the frequency ratio and damping ratio (Guo, $\mathrm{Xu}, \mathrm{Fu}, \& \mathrm{Zhang}, 2010)$. In this case, the frequency ratio $(\lambda)$ is equal to 1 . Hence, the transmissibility shown in Eq. (2) is used to calculate the total damping ratio (Gtotal) that occurred in the HDB system, as the parameter $\lambda$ and $\operatorname{Tr}$ at peak are known. The damping ratio $(\zeta)$ may be derived from Eq. (2) and written as

$$
\xi=\frac{1}{2} \sqrt{\frac{1}{T_{r}^{2}-1}}
$$

Table 3 presents the averaged damping ratio of HDB foams calculated based on measurement data obtained from the transmissibility test. It is assumed that the damping effects generated in the HDB foam system are caused by (i) frictional losses from bearings during vertical movement of the top plate, and (ii) the HDB foam inserted. Based on the results obtained, the total damping ratio (לtotal) decreases when the thickness of the HDB foam increases, except for the RRRR HDB foam, as shown in Table 3. This is because rigid HDB foam is a hard and brittle material. Therefore, when the transmission occurs in the system, the response and damping are not consistent due to the characteristics of the material. In this damping property study, HDB flexible foams show that they can provide higher damping than HDB rigid foam. However, the variations may be due to the factors of the particles size and the isotropy properties of the compact particles structure developed. Based on previous research by Chandra, Singh, and Gupta (1999), Strong and Rotz (1999), and (Ravi Sankar et al., 2010) this is because the damping of vibration in polymeric material is most related to the effect of 
fillers and the morphology of the foam, and these causes can be related to this study of HDB. The damping ratio calculated also revealed that FF HDB foam has good vibration damping, the values of which are 0.61 for displacement at $1 \mathrm{~mm}$ and 0.67 at $1.5 \mathrm{~mm}$. Besides, the damping ratio for acceleration at $0.1 \mathrm{~g}$ is 0.58 and at $0.15 \mathrm{~g}$ is 0.62 . From this study, reducing the thickness of the HDB flexible foam increases the damping ratio up to $36 \%$.

Table 3. Damping ratio of flexible and rigid HDB obtained from measured data.

\begin{tabular}{|c|c|c|c|c|}
\hline \multirow[t]{2}{*}{ Index } & \multicolumn{4}{|c|}{$\begin{array}{l}\text { Damping in HDB foam system } \\
(\zeta \text { total })\end{array}$} \\
\hline & \multicolumn{2}{|c|}{ Displacement } & \multicolumn{2}{|c|}{ Acceleration } \\
\hline Base Excitation & $1 \mathrm{~mm}$ & $1.5 \mathrm{~mm}$ & $0.1 \mathrm{~g}$ & $0.15 \mathrm{~g}$ \\
\hline $\mathrm{FF}$ & 0.61 & 0.67 & 0.58 & 0.62 \\
\hline FFF & 0.42 & 0.48 & 0.55 & 0.61 \\
\hline FFFF & 0.39 & 0.44 & 0.53 & 0.59 \\
\hline RR & 0.56 & 0.64 & 0.54 & 0.58 \\
\hline RRR & 0.38 & 0.44 & 0.52 & 0.59 \\
\hline RRRR & 0.38 & 0.46 & 0.54 & 0.60 \\
\hline
\end{tabular}

\section{CONCLUSIONS}

In conclusion, the ability of the flexible HDB to absorb vibration is greater than rigid HDB and flexible HDB also gives higher damping than rigid HDB. Two layers of HDB give a better damping ratio than three or four layers of HDB. Different thicknesses of $\mathrm{HDB}$, whether flexible or rigid, have different resonance peaks and resonance frequencies. There is a critical frequency at which the vibration transmissibility is high, and above this critical frequency the vibration transmissibility falls and is less than 1 , except for the rigid HDB. In summary, the mass, density and characteristics of the HDB structure as shown in SEM influence the vibration absorption of the system. This HDB can be applied in any application, but especially in the automotive field and manufacturing packaging.

\section{ACKNOWLEDGEMENTS}

The author would like to thank Universiti Tun Hussein Onn Malaysia (UTHM), Johor and the Malaysian Government for supporting this research under Malaysian Technical University Center of Excellence (MTUN-COE) vote C014.

\section{REFERENCES}

Alonso, M. V., Auad, M. L., \& Nutt, S. (2006). Short-fiber-reinforced epoxy foams. Composites Part A: Applied Science and Manufacturing, 37(11), 1952-1960.

Chandra, R., Singh, S. P., \& Gupta, K. (1999). Damping studies in fiber-reinforced composites-a review. Composite structures, 46(1), 41-51.

Dai, X., Liu, Z., Wang, Y., Yang, G., Xu, J., \& Han, B. (2005). High damping property of microcellular polymer prepared by friendly environmental approach. The Journal of supercritical fluids, 33(3), 259-267. 
FSA. (2012). Waste cooking oil. Retrieved 8/7/2102, from http://www.food.gov.uk/ business_industry/guidancenotes/foodguid/wastecook ingoil\#.ULjq0uRthlM.

Guo, Y., Xu, W., Fu, Y., \& Zhang, W. (2010). Comparison studies on dynamic packaging properties of corrugated paperboard pads. Engineering, 2(5).

Inman, D. J., \& Singh, R. C. (2001). Engineering vibration. New Jersey: Prentice Hall

Joshi, G., Bajaj, A. K., \& Davies, P. (2010). Whole-body vibratory response study using a nonlinear multi-body model of seat-occupant system with viscoelastic flexible polyurethane foam. Industrial health, 48(5), 663-674.

Ravi Sankar, H., Vamsi Krishna, P., Bhujanga Rao, V., \& Bangaru Babu, P. (2010). The effect of natural rubber particle inclusions on the mechanical and damping properties of epoxy-filled glass fibre composites. Proceedings of the Institution of Mechanical Engineers, Part L: Journal of Materials Design and Applications, 224(2), 63-70.

Rivin, E. I. (2003). Passive vibration isolation. New York: ASME press

Rus, A. Z. M. (2009a). Effect of titanium dioxide on material properties for renewable rapeseed and sunflower polyurethane. International Journal of Integrated Engineering, 1(1), 15-22.

Rus, A. Z. M. (2009b). Material properties of novelty polyurethane based on vegetable oils. Paper presented at the The 11 th International Conference on QiR (Quality in Research), Depok, Indonesia, Depok, Indonesia.

Rus, A. Z. M. (2010). Polymers from renewable materials. Science progress, 93(3).

Rus, A. Z. M., Kemp, T. J., \& Clark, A. J. (2008). Degradation studies of polyurethanes based on vegetable oils. Part 1. Photodegradation. Progress in Reaction Kinetics and Mechanism, 33(4), 363-391.

Saunders, J. H., \& Frisch, K. C. (1978). Polyurethanes: Chemistry and technology. New York: John Wiley.

Strong, A. B., \& Rotz, C. (1999). Damping in composites: It's there, but is it understood? Composites Fabrication, 15(2), 30-34.

Su, J. C. P., Wang, L., \& Ho, J. C. H. (2010). The impacts of technology evaluation on market structure for green products. . Journal of Mathematical and Computer Modelling,, 55, 1381-1400.

SWP. (2012). Solid waste program. http://dec.alaska.ov/eh/sw

Thomson, W. T. (1993). Theory of vibration with applications, 1993. New Jersey: : A Simon \& Schuster Company.

Ulrich, H. (1983). Urethane polymers. New York: John Wiley.

Vaidya, U. K., Pillay, S., Bartus, S., Ulven, C. A., Grow, D. T., \& Mathew, B. (2006). Impact and post-impact vibration response of protective metal foam composite sandwich plates. Materials Science and Engineering: A, 428(1), 59-66.

White, S. W., Kim, S. K., Bajaj, A. K., Davies, P., Showers, D. K., \& Liedtke, P. E. (2000). Experimental techniques and identification of nonlinear and viscoelastic properties of flexible polyurethane foam. Nonlinear Dynamics, 22(3), 281-313.

Wong, C. L., \& Schueneman, H. H. (1997). Cushion vibration testing comparing sine vs random vibration excitation of different spring-mass models. San Jose: WestPark Inc. .

Zaretsky, E., Asaf, Z., Ran, E., \& Aizik, F. (2012). Impact response of high density flexible polyurethane foam. International Journal of Impact Engineering, 39(1), 1-7. 